\title{
Ultrastructural Studies of Germ Cell Development and the Functions of Leydig Cells and Sertoli Cells associated with Spermatogenesis in Kareius bicoloratus (Teleostei, Pleuronectiformes, Pleuronectidae)
}

\author{
${ }^{\dagger}$ Hee-Woong Kang ${ }^{1}$, Sung Hwan Kim², and Jae Seung Chung ${ }^{3}$ \\ ${ }^{I}$ East Sea Fisheries Research Institute, National Institute of Fisheries Science, Gangneung 25435, Korea \\ ${ }^{2}$ Faculty of Marine Applied Biosciences, Kunsan National University, Gunsan 54150, Korea \\ ${ }^{3}$ Dept. of Urology, College of Medicine, Inje University, Busan 48108, Korea
}

\begin{abstract}
The ultrastructures of germ cells and the functions of Leydig cells and Sertoli cells during spermatogenesis in male Kareius bicoloratus (Pleuronectidae) were investigated by electron microscope observation. Each of the well-developed Leydig cells during active maturation division and before spermiation contained an ovoid vesicular nucleus, a number of smooth endoplasmic reticula, well-developed tubular or vesicular mitochondrial cristae, and several lipid droplets in the cytoplasm. It is assumed that Leydig cells are typical steroidogenic cells showing cytological characteristics associated with male steroidogenesis. No cyclic structural changes in the Leydig cells were observed through the year. However, although no clear evidence of steroidogenesis or of any transfer of nutrients from the Sertoli cells to spermatogenic cells was observed, cyclic structural changes in the Sertoli cells were observed over the year. During the period of undischarged germ cell degeneration after spermiation, the Sertoli cells evidenced a lysosomal system associated with phagocytic function in the seminiferous lobules. In this study, the Sertoli cells function in phagocytosis and the resorption of products originating from degenerating spermatids and spermatozoa after spermiation. The spermatozoon lacks an acrosome, as have been shown in all teleost fish spermatozoa. The flagellum or sperm tail of this species evidences the typical 9+2 array of microtubules.
\end{abstract}

Key words : Kareius bicoloratus, spermatogenesis, germ cell, Leydig cells, Sertoli cells

\section{INTRODUCTION}

The stone flouder, K. bicoloratus is a commercial important edible fish that is widely consumed in East Asian countries, including Korea, China, and Japan (Kim \& Kang, 1993; Kim et al., 2005). In Korea, this fish is mainly found on the southern and western coasts. Recently, many studies on the functions of the Leydig cells and Sertoli cells associated with spermatogenesis and stereogenesis have been conducted.
In particular, Leydig cells situated in the interlobular space in the testis in lower vertebrates such as Pisces and Amphibia are quite similar to the interstitial cells (Leydig cell) in the adult mammalian testes (Hyder, 1969; Gresik et al., 1973). In higher vertebrates, the Sertoli cells may well carry out a nutritive, contractile, or steroidogenic role (Nicholls \& Graham, 1972). Several studies have previously been conducted into $K$. bicoloratus. These studies have been primarily concerned with several aspects of reproduction, including egg and larval

\footnotetext{
Manuscript received December 30, 2015, Received in revised form January 8, 2016, Accepted January 15, 2016

${ }^{\dagger}$ Corresponding Author : Hee-Woong Kang, East Sea Fisheries Research Institute, NIFS, Gangneung 25435, Korea. Tel. : +82-33-660-8541, E-mail : hwgang@korea.kr

This is an Open Access article distributed under the terms of the Creative Commons Attribution Non-Commercial License (http:// creativecommons.org/licenses/by-nc/3.0) which permits unrestricted non-commercial use, distribution, and reproduction in any medium, provided the original work is properly cited.
} 
development (Kim \& Kim, 1989; Jun et al., 2002), growth and maturity (Mori et al., 1986), early life history (Minami, 1984; Moon, 1997), larval morphology (Han \& Kim, 1997), seedling production (Jun et al., 2000, 2001). To date, Leydig cells in the testes of teleosts were observed within the interstitium between the seminiferous lobules of the testis. Many authors have reported Leydig cells in clusters or groups located near blood vessels (Chung, 2008; Chung et al., 2010). Sertoli cells are well-known to be related with germ cell development and nutrient supply to germ cells during spermatogenesis (Pudney, 1993, 1996; Chung, 2008). In particular, the functions of Sertoli cells are involved in the ingestion of phagosomes and residual bodies by way of the process of phagocytosis by various lysosomes for the degeneration of spermatids and spermatozoa after spermiation (Chung \& Chang, 1995; Chung, 2008; Chung et al., 2010). Above all, the studies of Sertoli cells, and Leydig cells associated with the spermatogenesis of $K$. bicoloratus are required to understand the reproductive mechanism of this fish. However, the functions and activities of the Leydig cells associated with maturation division and steroid secretion have yet to be clarified (Pudney, 1996; Chung, 2008). Additionally, as a component of a broader investigation into the ultrastructures of various spermatogenesis-associated cells, the morphology and ultrastructure of fish sperm should be given careful consideration. If some characteristics obtained from sperm ultrastructure and the process of spermiogenesis can be phylogenetically analyzed, the results of the ultrastructural studies on fish spermatozoa can be expected to provide important information for the elucidation of relationship patterns among several fish groups (Jamieson, 1991; Mattei, 1991; Chung, 2008; Luo et al., 2011). To date, although many researchers have studied on spermatogenesis and ultrastructures and morphologies of sperms, little information is available on the ultrastructures of spermatic germ cells and the functions of the Sertoli cells and Leydig cells associated with spermatogenesis in this species. Therefore, it is very important to study germ cell differentiations and the functions of Leydig cells and Sertoli cells associated with spermatogenesis by the transmission electron microscopic observation. Beside spermatogenesis, the fate of undischarged germ cells such as spermatds and spermatozoa after spermiation should be clarified with the functions of Sertoli cells. Therefore, the purpose of the present study is to describe the ultrastructural characteristics of germ cell differentiations, and also clarify spermatogenesis and spermiation associated with Leydig cells and Sertoli cells.

\section{MATERIALS AND METHODS}

\section{Sampling}

A total of 120 specimens of $K$. bicoloratus, which were reared in the tank at the Buan hatchery, NIFS, were used for the study from January to December, 2009. After living fish were transported to the laboratory, the specimens were used for electron microscopic observations.

\section{Ultrastructural observations of germ cells, the} Leydig cells and Sertoli cells

For production of tissue specimens for TEM observations of testicular structure of $K$. bicoloratus excised pieces of testes were cut into small pieces, and a fixation was made in $2.5 \%$ glutaraldehyde- $2 \%$ paraformaldehyde $(0.1 \mathrm{M}$ cacodylate buffer, $\mathrm{pH} 7.5$ ) for $2 \mathrm{~h}$ at $4^{\circ} \mathrm{C}$. A full rinsing was made by three times of repetition at around 30 minutes interval with $0.1 \mathrm{M}$ cacodylate buffer $(\mathrm{pH} 7.5)$, and a fixation was made in $2 \%$ osmium tetroxide $(0.2 \mathrm{M}$ cacodylate buffer, $\mathrm{pH} 7.5$ ) for $90 \mathrm{~min}$. at $4^{\circ} \mathrm{C}$. Tissue fragments after a fixation was dried by ethanol, transposed with propylene oxide, and embedded in an Epon-Araldite mixture. Ultrathin sections of Epon-embedded specimens were cut with glass knives on a Sorvall MT-2 ultramicrotome at a thickness of about 80-100 nm. Tissue sections were mounted on collodioncoated copper grids, doubly stained with uranyl acetate 
followed by lead citrate, and ultrathin sections were observed with a JEM 100 CX-2 (100kv) electron microscope.

\section{RESULTS}

\section{Ultrastructure of the testis}

The general internal structure of the testis of $K$. bicoloratus is similar to those of other flat fishes. The testes are paired elongated organs, attached to the dorsal wall of the body by a mesorchium. Both testes join caudally, converging in a central efferent duct system which is open to the exterior through the urogenital pore. The testis develop as a pair of sac-like structure bilaterally in the abdomen, however, it is not bilateral symmetry. Histological examination of teleost testes reveals that they possess an interstitial tissue and a germinal component, the latter being a germinal epithelium composed of germ cells that are supported by somatic Sertoli cells. The somatic cells are the Sertoli cells that are involved in the phagocytosis of residual bodies cast off by developing spermatids. Interlobular spaces are generally narrow. The interstitial region between the lobules contains blood vessels, clearly discernible islets of interstitial tissue can be defected between the developing seminiferous lobules. Within the interstitium, the steroidogenic Leydig cells produce testosterone which is involved in the meiotic division of germ cells. At this time, germ cells such as spermatogonia, spermatocytes or developing spermatids are found in the cysts in the seminiferous lobule, but germ cells in same developmental stage are existed in each cyst in the seminiferous lobule. Just inside each seminiferous lobule lie the Sertoli cells. At this time testicular developmental stages, the morphology and ultrastructure of the Sertoli cells show some characteristics of the cyclic changes.

\section{Electron microscope observations of germ cell}

\section{development during spermatogenesis}

Spermatogenesis occurs in the cysts in the seminiferous lobules as seen in other teleosts. Based on morphological and ultrastructural characteristics and the development of germ cells in the seminiferous lobules of the testis, for convenience, spermatogenesis can be divided into four successive stages: (1) spermatogonia, (2) spermatocyte, (3) spermatid, and (4) spermatozoon stages.

\section{1) Spermatogonial stage}

During this stage, primary spermatogonia (the largest germ cells) were individually surrounded by the elongated or triangular Sertoli cells, are approximately $7-8 \mu \mathrm{m}$ in diameter. Primary spermatogonia are localized in the germinal epithelium near the Sertoli cells. Primary spermatogonia contain a spherical nucleus (about $4 \mu \mathrm{m}$ in diameter) containing chromatin materials, and one or two nucleoli in the nucleus. And several mitochondria appear in the cytoplasm of the primary spermatogonium. Each Sertoli cell contains an elongated nucleus and several mitochondria in the cytoplasm, while the development of the cytoplasm is very weak. The primary spermatogonium divides mitotically to produce secondary spermatogonia which measured about 7 $\mu \mathrm{m}$ in length (Fig. 1). The secondary spermatogonia are spherical cells, smaller than the primary spermatogonia, have a spherical nucleus containing chromatin materials. Their cells contain the intermitochondrial cements, several mitochondria and a number of glycogen particles in the cytoplasm. In particular, intermitochondrial cements appear in the cytoplasm near the nuclear envelope of secondary spermatogonia. At this time, Secondary spermatogonia are surrounded by a few triangular Sertoli cells (Fig. 2).

\section{2) Spermatocyte stage}

Secondary spermatogonia develop into primary spermatocytes by the mitotic division. For convenience, the spermatocyte stage can be divided into two stages: the primary and secondary spermatocyte stages. In the primary spermatocyte stage, a developing Leydig cell during the maturation division in the interstitium appear near the cysts containing the primary spermatocytes in seminiferous lobules. 


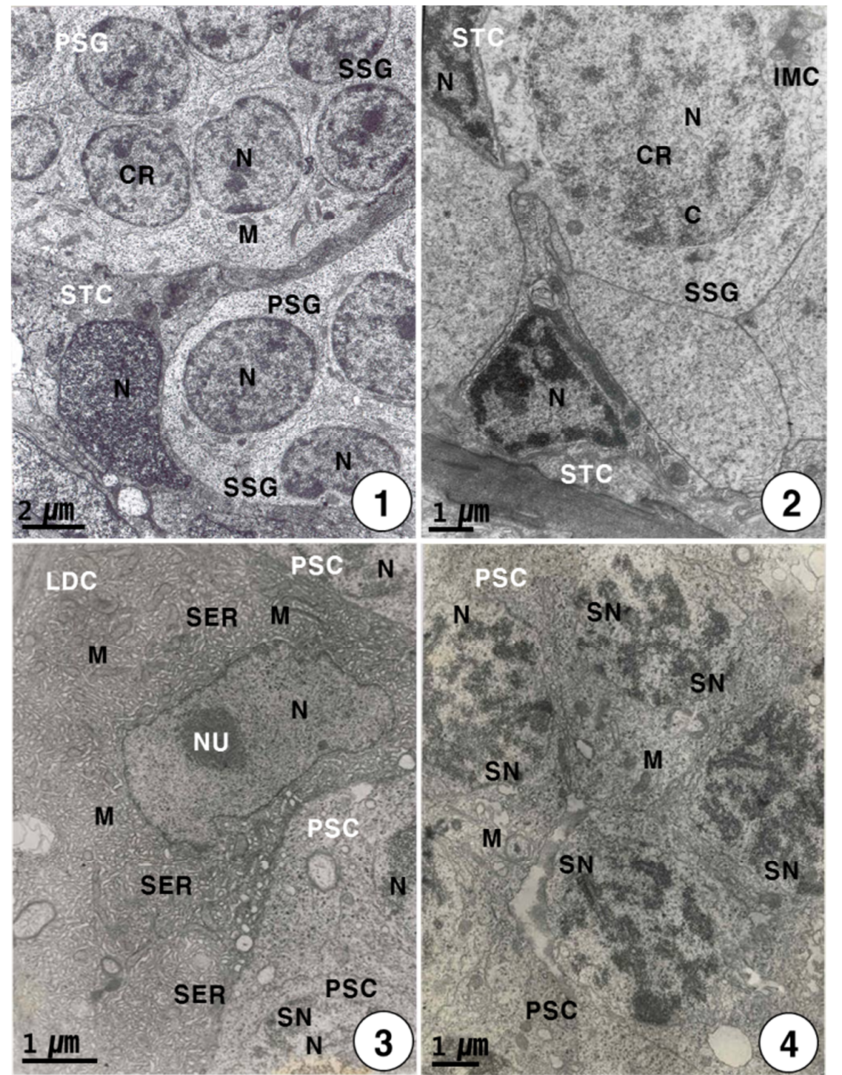

Figs. 1-4. Electron micrographs showing the early stage of spermatogenesis in male Kareius bicoloratus.

(1) Primary spermatogonia, secondary spermatogonia and elongated Sertoli cells containing large nuclei and several mitochondria. (2) Secondary spermatogonia containing the intermitochondrial cement in the cytoplasm, and triangular nuclei in the Sertoli cells.

(3) A Leydig cell which occurred during the first meiotic division containing a vesicular nucleus and mitochondria and undeveloped smooth endoplasmic reticulum. (4) primary spermatocytes containing several synaptonemal complexes in the nucleus, and several mitochondria and a few lipid droplets in the cytoplasm. Abbreviations: CR, chromatin materials; IMC, intermitochondrial cement; LDC, Leydig cell; M, mitochondrion; N, nucleus; NU, nucleolus; PSG, primary spermatogonium; SER, smooth endoplasmic reticulum; SN, synaptonemal complex; SSG, secondary spermatogonium; STC, Sertoli cell.
At this stage, the Leydig cell is irregular oval in shape, and appears near the cysts containing primary spermatocytes in the seminiferous lobule. Each of the developing Leydig cells (approximately $10.5-12.0 \mu \mathrm{m}$ in diameter) contains main three morphological, structural characteristics: a vesicular nucleus, ovoid or elongated mitochondria and a number of developing smooth endoplasmic reticula in the cytoplasm. At this time, primary spermatocytes (approximately 6.5$7.0 \mu \mathrm{m}$ in diameter) are oval in shape (Fig. 3). During the maturation division of the Leydig cell, the primary spermatocyte nucleus undergo morphological changes. In primary spermatocytes, several synaptonemal complexes in the nucleus appear in the prophase during the first meiotic division. During pachytene, synaptonemal complexes are particularly evident, and the nucleolus in the nucleus is not visible (Fig. 4). The primary spermatocyte gives rise to secondary spermatocytes by the first meiotic division. Secondary spermatocytes are oval in shape, the nucleus contains the reduced chromosomes (the haploid number of chromosomes), but duplicated within the cysts. Compared to primary spermatocytes, secondary spermatocytes (approximately 5.5-6.5 $\mu \mathrm{m}$ in diameter) show the decrease in nuclear sizes. They possess oval nuclei. However, the nucleolus is not visible, and chromosomic masses in the nucleus are frequently found near the Sertoli cell. The cytoplasm is reduced and contains several mitochondria and a few vacuoles. In the secondary spermatocyte stage, it is sometimes hard to distinguish the cellular limits (Fig. 5). A developing Leydig cell in the interstitium have three morphological characteristics of a developing vesicular nucleus, gradually developing mitochondria with tubular cristae, and developing smooth endoplasmic reticula during the meiotic division (Fig. 6).

\section{3) Spermatid stage}

Secondary spermatocytes give rise to spermatids by the second meiotic division. Spermatids have different stages 
of spermiogenesis by the degree of heterochromatin condensation. Spermatids undergo morphological changes and a size reduction during spermiogenesis. For convenience, the spermatid stages during spermiogenesis can be divided into two stages: the early and late stages. In the early stage of spermatids (approximately 4.0-4.5 $\mu \mathrm{m}$ in diameter) during spermiogenesis, the nuclei are oval or round in shape, and their sizes of the nuclei become smaller. At this stage, in particular, condensation of electron-dense heterochromatin materials appears in the nucleus (Fig. 7). In the early stage of spermatid during spermiogenesis, the cell morphology and nuclear shape of the developing Sertoli cell are triangular or oval in shape. In particular, condensation of electron-dense heterochromatin materials appears in the nucleus of the triangular Sertoli cell. In particular, desmosome between Sertoli cells, several mitochondria, a large quantity of glycogen particles, and a few lipid droplets appear in the cytoplasm of Sertoli cells (Fig. 8). In the late stage of spermatid during spermiogenesis, particularly, elongated mitochondria with cristae and a large quantity of glycogen particles appear in the cytoplasm of a triangular Sertoli cell. Therefore, at this time, the activity of the Sertoli cell is very high, although no clear evidence of steroidogenesis is found (Fig. 8). In the late stage of spermatid during spermiogenesis (during the periods of active meiotic division and before spermiation), welldeveloped Leydig cells (about 11.3-13.5 $\mu \mathrm{m}$ in diameter), which fill the central regions of the interstitium between seminiferous lobules, are ovoid or cuboidal cells, and each cell contains an ovoid vesicular nucleus containing slightly condensed chromatins around the nuclear envelope. Most of the cytoplasm is occupied by tubules of smooth endoplasmic reticulum, tubular or vesicular cristae of mitochondria, and several lipid droplets appear within fully differentiated and apparently actively secreting Leydig cells. Thus, Leydig cells show several structural characteristics, as have been observed in typical steroidogenic

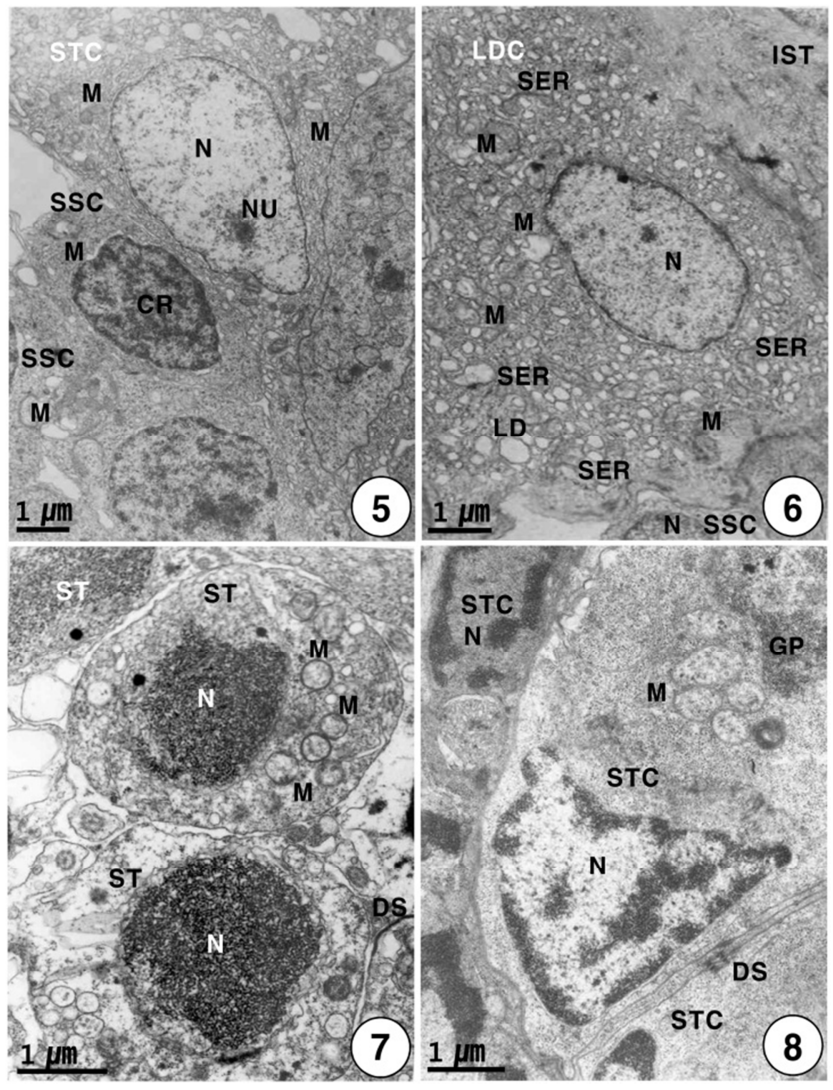

Figs. 5-8. Electron micrographs showing spermatogenesis in male Kareius bicoloratus. (5) Secondary spermatocytes containing heterochromatin materials in the nucleus, and a Sertoli cell having a remarkable nucleolus. (6) A developing Leydig cell in the interstitium during maturation division containing large vesicular nucleus and a large quantity of smooth endoplasmic reticula in the cytoplasm. (7) Spermatids in the early stage of spermiogenesis containing oval nuclei with electron-dense heterochromatins and several mitochondria in the cytoplasm. (8) Well-developed Sertoli cells in the late stage of spermiogenesis containing a triangular nucleus, several mitochondria, a large number of glycogen particles, and the appearance of desmosome between the Sertoli cells. Abbreviations: DS, desmosome; GP, glycogen particle; IST, interstitium; LD, lipid droplet; LDC, Leydig cell; M, mitochondrion; N, nucleus; SER, smooth endoplasmic reticulum; SSC, secondary spermatocyte; ST, spermatid; STC, Sertoli cell. 
cells (Fig. 9).

During the spermiogenesis, the morphology of the spermatid nucleus changes gradually, and several mitochondria and centrosome move to a position just behind the nucleus of the spermatid. At this time, the centrosome and mitochondria move to beneath the nucleus (Fig. 10). In the late stage of spermatid during spermiogenesis, the final spermatids are still in the cyst. At this time, two centrioles are initially located nearly the nuclear envelope; the proximal centriole appears near the nuclear envelope, and the distal centriole forms the basal body of the flagellum. The basal body gives rise to the flagellum. In the cyst, each flagellum is formed from each centriole prior to the mitochondrial arrangement that will become the midpiece. The final spermatids, which still contain a large amount of cytoplasm, eliminate the excess (Fig. 11).

\section{4) Spermatozoon stage}

In general, mature spermatozoa appear near the Sertoli cell containing lipid droplets, glycogen particles and mitochondria appear in the cytoplasm. At this time, the morphology of mature spermatozoon is oval in shape, condensation of electron-dense heterochromatin materials in the nucleus appears, and also two centrioles appear beneath the nucleus: the proximal centriole appear near the nuclear envelope, and the distal centriole forms the basal body of the flagellum and give rise to the flagellum. The flagellum is formed from the basal body. The sperm head is oval in shape, particularly under the sperm nucleus, the cytoplasmic collar, which is formed by $8-10$ mitochondria surrounding flagellum axial filament, is observed around the midpiece of spermatozoon. And also the coat of the spermatozoa is shed into the cytoplasm, relatively deep cytoplasmic canals appear around the midpiece of the spermatozoa. At this time, the activity of the Sertoli cell is very high, although no clear evidence of steroidogenesis is found. In the same stage, the differentiation of spermatozoa is completed, the

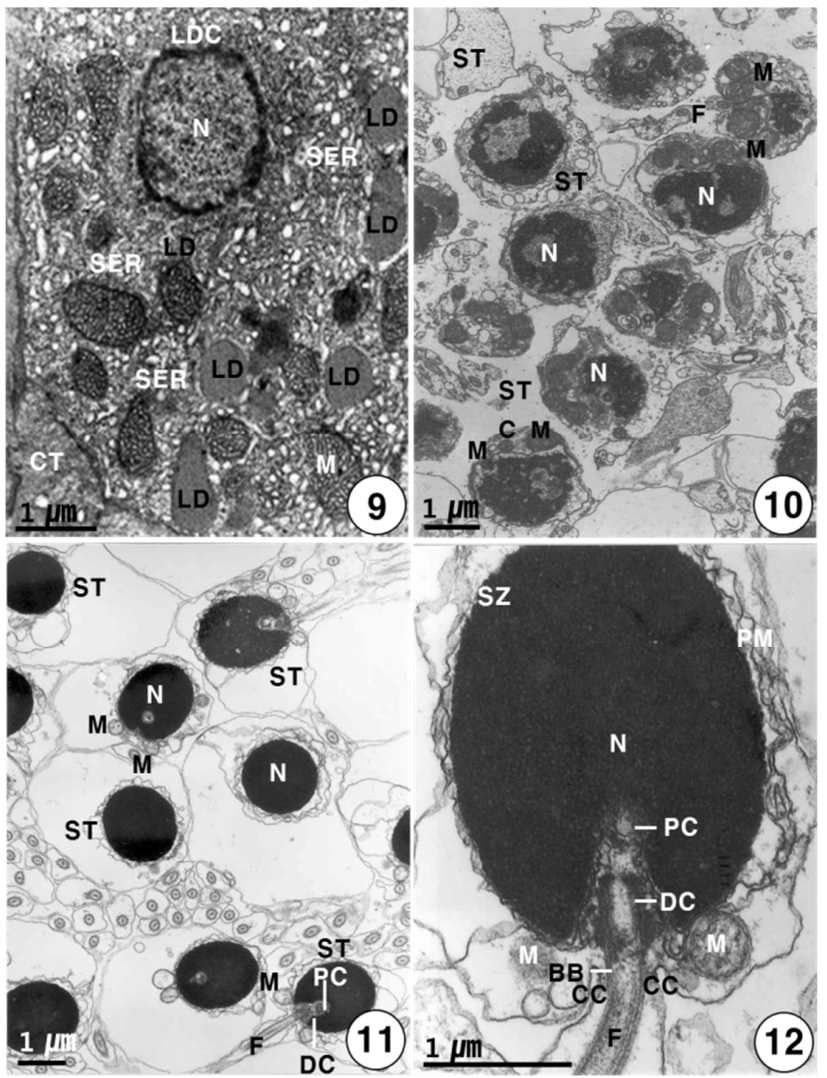

Figs. 9-12. Electron micrographs showing spermiogenesis in male Kareius bicoloratus. (9) Well-developed Leydig cell during the periods of active meiotic division and before spermiation containing a vesicular nucleus, a large quantity of smooth endoplasmic reticulum, oval or elongated mitochondria with tubular or vesicular cristae, and several lipid droplets in the cytoplasm. (10) A number of spermatids in the late stage of spermiogenesis containing centriolar complex and mitochondria. (11) A number of spermatids in the late stage of spermiogenesis containing oval or round sperm nuclei which is densely packed with chromatin materials. centriolar complex (proximal and distal centrioles) and mitochondria. (12) A completed spermatozoon containing an oval sperm nucleus with no acrosome, and the proximal centriole, distal centriole, the appearance of the cytoplasmic canals in the sperm midpiece and flagellum. Abbreviations $\mathrm{BB}$, basal body; C, centriolar complex; CT, connective tissue; DC, distal centriole; DS, desmosome; F, flagellum; LD, lipid droplet; LDC, Leydig cell; M, mitochondrion; N, nucleus; $\mathrm{PC}$, proximal centriole; PM, plasma membrane; SER, smooth endoplasmic reticulum; ST, spermatid. 
heads of these spermatozoa are created at the periphery of the cysts toward the lumen of seminiferous lobules, with their tails oriented in the opposite direction. The spermatozoon of $K$. bicololatus has a head, a small midpiece, and a single flagellum. The proximal centriole is anterior and perpendicular to the distal centriole. Therefore, the sperm structure of this species shows a primitive type, as found in the species that perform external fertilization. The oval or round sperm nucleus of this species is densely packed with chromatin material. The spermatozoon of $K$. bicoloratus lacks an acrosome, as have been shown in other teleost fish. The sperm head is approximately $3 \mu \mathrm{m}$ in length. In the midpiece of the sperm, the proximal centriole, distal centriole and cytoplasmic canal appear beneath the nucleus, and the sperm tail (flagellum) is about $40 \mu \mathrm{m}$ in length (Figs. 12, 14). The sperm flagellum contains an axoneme with nine doublets of peripheral microtubules and two central singlet microtubules; the flagellum shows the typical 9+2 array of microtubules, interconnected by dynein and nexine arms. Transverse sectioned sperm midpiece showed $9+2$ region of axoneme through 8-10 mitochondria and cytoplasmic canal near an axonneme (Fig. 13). Two flagellum lateral fins are shown in the cross-section of the flagellum of the sperm, as found in species that perform external fertilization (Fig. 15).

5) Degeneration of the Sertoli cells and the Leydig cells

Just before spermiation, Sertoli cells have irregular or slightly triangular nuclei, and some lysosomes begin to appear near the interdigitation of the Sertoli cells. And the Sertoli cells produce slender cytoplasmic processes into the cyst lumen. After numerous spermatozoa discharged, the Sertoli cells have irregular pycnotic nuclei. At this time, Sertoli cells undergo active phagocytosis by various lysosomes, and slender cytoplasmic processes protrude into the cyst lumen. During the period of germ cell degeneration, the cyst walls and a part of the basement membrane of the

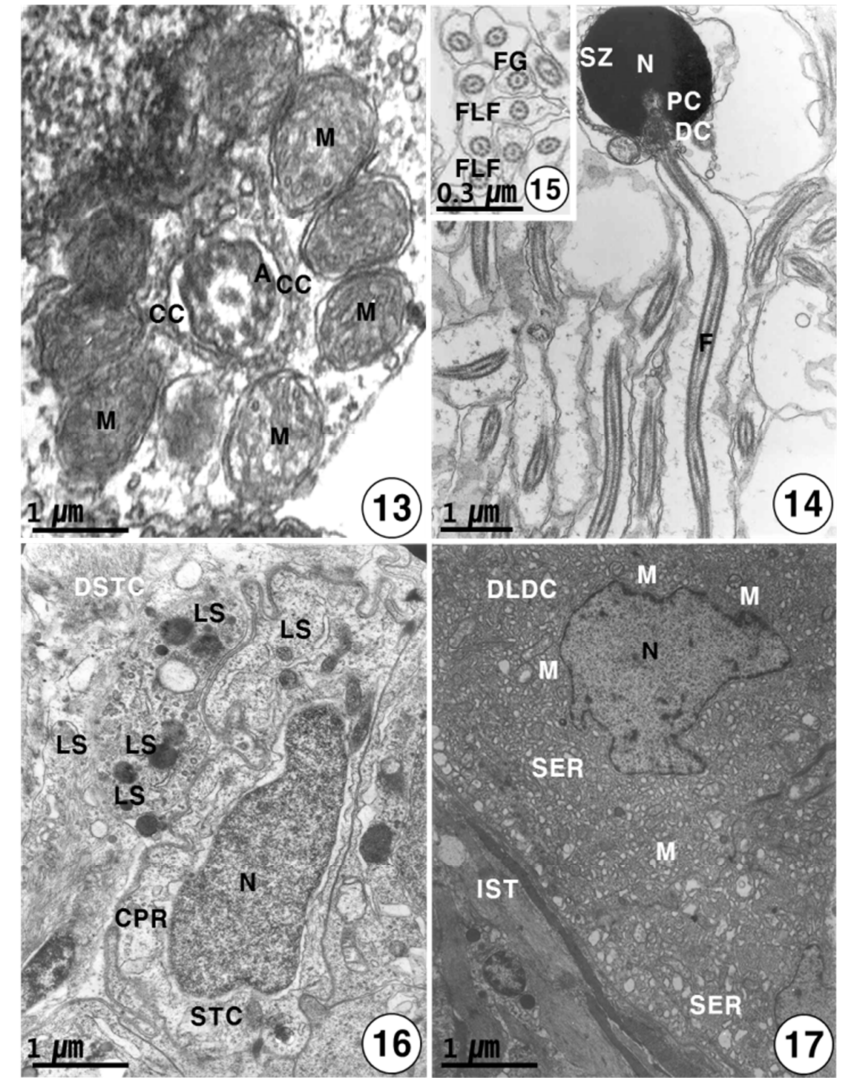

Figs. 13-17. Electron micrographs showing completed spermatozoa degenerating Sertoli cells and degenerated Leydig cells in male Kareius bicoloratus. (13) Transverse section of $9+2$ region of axoneme through mitochondria and cytoplasmic canal being composed of eight to ten mitochondria. (14) A completed spermatozoon showing an oval sperm nucleus with no acrosome. (15) The cross-sectioned sperm tail flagellum containing two flagellum lateral fins. (16) Degenerating Sertoli cells during spermiation containing an irregular nucleus, several phagosomes, various kinds of lysosomes, the degenerated sperms or spermatids and cytoplasmic processes after spermiation. (17) Degenerated Leydig cell containing the irregular nucleus, degenerated small smooth endoplasmic reticula and small number of mitochondria. Abbreviations: A, axoneme; CC, cytoplasmic cannal; CPR, cytoplasmic process; DC, distal centriole; DLDC, degenerated Leydig cell; DSTC, degenerating Sertoli cell; FG, flagellum; FLF, flagellum lateral fin; IST, interstitium; LS, lysosome; $\mathrm{M}$, mitochondrion; $\mathrm{N}$, nucleus; $\mathrm{PC}$, proximal centriole; STC, Sertoli cell; SER, smooth endoplasmic reticulum; SZ, spermatozoon. 
Sertoli cells are broken around the periphery of the seminiferous lobules by various lysosomes. In particular, slender cytoplasmic processes are observed in the cytoplasm near the pycnotic nuclear envelope of Sertoli cells. Degenerating spermatids and spermatozoa by various lysosomes in the cytoplasm of the Sertoli cells. Occasionally, large phagosomes, residual body and autophagic vacuoles are observed within the cytoplasm of the Sertoli cell (Fig. 16). After spermiation, the clusters of degenerating Leydig cells are also present in degenerated interstitium between seminiferous lobules, at that time, the nucleus of the Leydig cell is irregular in shape. Notably, degenerating smooth endoplasmic reticulum and several small mitochondria also appear in the cytoplasm of degenerating Leydig cells near degenerating spermatids in the cysts (Fig. 17).

\section{DISCUSSION}

Recently, several authors (Grier, 1980, 1981; Grier \& Linton, 1977) reported that regarding the anatomical disposition of the germinal tissue, the organization of the teleost testes can be classified into two basic types of structural arrangement: (1) a tubular type with no lumen, and (2) a lobular type with a central lumen where cysts develop along the length of the lobules (most teleost species).

Cystic spermatogenesis, which is characteristics of most teleosts, occurs in cysts. In this study, the type of spermatogenesis of K.bicoloratus was found to be cystic spermatogenesis. Germ cells in the cysts were found to be in various stages of development. However, germ cells in the same developmental stage were found in each cyst in the lobular lumen, as seen in B. Pectinirostris (Chung, 2008). Therefore, ultrastructural study of the testicular structure, $K$. bicoloratus belongs to a lobular type.

Chung (2008) reported that well-developed Leydig cells during the period of active meiotic division have three major morphological characteristics: (1) a vesicular nucleus,
(2) mitochondria with tubular cristae, (3) smooth endoplasmic reticulum. Of these three characteristics, vesicular nuclei have been observed in the steroid-secreting cells of teleosts (Follenius, 1964; Asahina et al., 1985; Chung \& Chang, 1995). Colombo \& Burighel (1974) stated that lipid droplets and dense osmiophilic bodies were also occasionally found in the cytoplasm of Leydig cells, and that this combination of organelles is typical of steroidogenic cells.

In this study, well-developed Leydig cells of $K$. bicoloratus were found to have three major morphological characteristics reported by some authors. Therefore, it appears that Leydig cells, as typical steroidogenic cells, are involved in male sex steroidogenesis. The activities of the Leydig cells were strong during spermatogenesis, especially, the period of the meiotic division (maturation division) and before spermiation, however, the activities of the Leydig cells did not show a cyclic change during the year, unlike the activities of the Sertoli cells showed a cyclic and seasonal changes with germ cell developmental stages associated with testicular maturation and degeneration.

In this study, the accumulation of lipid droplets in the cytoplasm of the Leydig cells of K.bicoloratus appeared during the periods of testicular development and maturation, indicative of active steroidogenesis, as seen in S. shlegeli (Chung \& Chang, 1995) and B. pectinirostris (Chung, 2008). Thus, Leydig cells in the testis of this species showed morphological characteristics of a typical steroidogenic cell. Exceptionally, however, a few authors (Follenius \& Porte, 1960; Follenius, 1968; Gresik et al., 1973) reported that lipid droplets were absent in healthy Leydig cells of teleost species. Therefore, the presence or absence of lipid droplets in the cytoplasm of Leydig cells varied with teleost species.

Regarding the functions of the Sertoli cells in the seminiferous lobules of teleost, Gresik et al. (1973) reported that the Sertoli cell has three functions: (1) nutrition, (2) phagocytosis, and (3) steroidogenesis. Chung (2008) reported 
that mitochondria, endoplasmic reticula, the large number of glycogen particles, and a few lipid droplets were present in the cytoplasm of mature Sertoli cells of $B$. pectinirostris. He supposed that in particular, glycogen particles in Sertoli cells appeared to be involved in spermatid nutrition during spermiogenesis. In this study, most of Sertoli cells of $K$. bicoloratus contained a large number of glycogen particles and a few lipid droplets during the period of multiplication of spermatogonia and spermiogenesis of spermatids. Thereafter, the numbers of glycogen particles and lipid droplets were subsequently reduced during spermiation. However, there is no indication of a transfer of nutrients to the spermatids during spermatogenesis, and the fine structure of the Sertoli cells did not provide clear evidence of stereroidogenesis or steroid activity.

Van Vuren \& Soley (1990) reported that after spermiation, cytoplasmic processes, particularly the long slender variety that encircle patches of whole sperm cells, are an indication of the phagocytic properties of Sertoli cells of Tilapia rendalli. Lo Nostro et al.(2003) reported that the lysosomal systems of Sertoli cells phagocytose residual bodies and undischarged germ cells, and they supposed that the uptake of residual bodies may be facilitated by the activity of Sertoli cells in many teleosts.

In this study, phagosomes containing degenerating spermatids and spermatozoa, lipid materials (lipid droplets and globular lipid bodies), and residual bodies were observed within the Sertoli cell cytoplasm. Large phagosomes, which are formed by phagocytosis and various lysosomes, were observed in the Sertoli cells. Long, slender cytoplasmic processes encircling patches of whole sperm cells appeared in the cytoplasm of the Sertoli cell. After residual bodies were phagocytosed, several autophagic vacuoles appeared in the cytoplasm of the Sertoli cell. After spermiation, Sertoli cells in the testes undergo degeneration by various lysosomes and are presumed to be resorbed. In this study, the characteristics of phagocytosis in Sertoli cells in $K$. bicoloratus were similar to the results reported by Van Vuren \& Soley (1990) and Lo Nostro et al. (2003).

Regarding phagocytosis of residual bodies, compared the results of fishes with those in mammals, there are some differences and similarity in the studies of phagocytosis of residual bodies. Chung (2008) reported that in teleosts such as B. pectinirostris, various lysosomes in Sertoli cells phagocytose and lyse the residual bodies that detach from spermatids after spermiation, and lipid materials (a few lipid droplets and granular lipid bodies) in Sertoli cell cytoplasm may then be produced by phagocytosis of residual bodies. In case of phagocytosis of residual bodies in mammals, Morales et al. (1985) and Sylvester et al. (1989) also reported that after spermiation, residual bodies, which are composed of large vacuoles, multivesicular bodies, condensed mitochondria, and lipid droplets, appeared in the Sertoli cell cytoplasm of rats. In particular, residual bodies are initially covered by thin cytoplasmic processes of Sertoli cells. Thus, in this study, these similar phenomena reported by Chung (2008) were also found in Sertoli cell cytoplasm of $K$. bicoloratus.

On the whole, In this study, morphological characteristics in the Sertoli cell nuclei of this species showed a cyclic change according to germ cell developmental stages in the seminiferous loubles of the testis, In the early developing stages of spermatogonia and spermatocyte, the morphologies of the Sertoli cell nuclei were triangular or elongated oval nuclei, and in the early stage of spermatids during spermiogenesis, those of the Sertoli cell nuclei were triangular in shape. However, in the late stage of spermatids during spermiogenesis, those of the Sertoli cell nuclei were elongated oval or oval in shape. In the mature stages of sperm development and after spermiation, the Sertoli cells contained an elongated oval nucleus, while after spermiation, the morphologies of the Sertoli cell nuclei show degenerating wrinkled oval or irregular forms in shape.

Poirier \& Nicholson (1982) reported that, in the case of species that perform external fertilization, the spermatozoa 
of the teleost fishes are considered to be the primitive type, with a round nucleus and short midpiece containing a few mitochondria, and a tail consisting of a long flagellum. In the present study, the spermatozoon of $K$. bicoloratus shows a typical primitive type, and externally-fertilizing sperm.

The spermatozoon lack an acrosome, as in all teleost fish spermatozoa (Romagosa et al., 1999; Chung \& Chang, 1995; Chung, 2008). This fact is generally related to the presence of an egg micropyle (Romagosa et al., 1999; Chung, 2008). Two masses of mitochondrial materials lies on two sides, the nucleus of the spermatozoon is asymmetrical. The type and structure of the sperm of this species are of the primitive type, and are a spermatozoon with a 9+2 pattern flagellum. According to the reports described by Mattei (1988) and Lo Nostro et al. (2003), the spermatozoon of this species belongs to the uniflagellate anacrosomal aquasperm group, and are the externally-fertilizing species as reported in B. pectinirostris (Chung, 2008).

Jamison (1989) reported that in case of most externallyfertilizing sperm, flagellum lateral fins on the flagellum of the spermatozoon are present. In this study, flagellum lateral fins on the flagellum of the spermatozoon of $K$. bicoloratus are present as seen in most externally-fertilizing sperm. Therefore, the results of this study are in agreement with those reported by Jamieson (1989).

\section{ACKNOWLEDGMENTS}

This work was supported by a grant from the National Institute of Fisheries Science (R2016003).

\section{REFERENCES}

Asahina K, Suzuki K, Aida K, Hibiya T, Tamaoki BI (1985) Relationship between the structures and steroidogenic functions of the testes in the Urhaze-goby (Glossogoviu solivaceus). Gen Comp Endocrinol 57:281-292.
Chung EY (2008) Ultrastructure of germ cells, the Leydig cells, and Sertoli cells during spermatogenesis in Boleophthalmus pectinirostris (Teleostei, Perciformes, Gobiidae). Tissue \& Cell 40:195-205.

Chung EY, Chang YJ (1995) Ultrastructural changes of germ cell during gametogenesis in Korean rockfish, Sebastes schlegeli. J Kor Fish Soc 28:736-752.

Chung EY, Yang YC, Kang HW, Choi KH, Jun JC, Lee KY (2010) Ultrastructure of germ cells and the functions of Leydig cells and Sertoli cells associated with spermatogenesis in Pampus argenteus (Teleostei: Perciformes: Stromateidae). Zoological Studies 49:39-50.

Colombo L, Burighel P (1974) Fine structure of the testicular gland of the black goby Gogius jozo L. Cell Tissue Res 154:39-45.

Follenius E (1964) Innervation des cellules interstitielles chezunpoission téléostéen Lebistes reticulates L. Etude aumicroscopeélectronique. CR AcadSci259:228-230.

Follenius E (1968) Cytologieet cytophysiologie des cellulesinterstitielles de I'Epinoche: Gasterrosteus acleatus L. Etude au microscope électronique. Gen Comp Endocr 11:198-219.

Follenius E, PorteA (1960) Cytologie fine des cellules interstitielles dutesticule du poisson Lebistes reticulates $\mathrm{R}$. Experientia 16:190-192.

Gresik EW, Quirk JG, Hamiltonm JB (1973) A fine structural and histochemical study of the Leydig cell in the testis of the teleost, Oryzias latipes (Cyprinidontiformes). Gen Comp Endocrinol 20:86-98.

Grier HJ (1980) Structural evidence for two different testicular types I teleost fishes. Am J Anat 159:331-345.

Grier HJ (1981) Cellular organization of the testis and spermatogenesis in fishes. Am Zool 21:345-357.

Grier HJ, Linton JR (1977) Ultrastructural identification of the Sertoli cell in the testis of the northern pink Esox lucius. Am J Anat 149:283-288.

Han KH, Kim YU (1997) Larval morphology of stone 
flounder, Kareius bicoloratus. Bull Fish Sci Inst Yosu Nat Univ 6:39-47. (in Korean)

Hyder M (1969) Histological studies on the testis of Tilapia leucostita and other species of the genus Tilapia (Pisces: Teleostei) Trans. Amer Microsc Soc 88:211-231.

Jamieson BGM (1989) Complex spematozoon of the live bearing half-beak, Hemirhamphodon pogonognathus (Bleeker): ultastructural description (Euteleostei, Atherinomorpha, Beloniformes). Gamete Res 24:247-259.

Jamieson BGM (1991) Superorder acanthopterygii.In: Jamieson BGM, editor. Fish Evolution and Systematics -: Evidence from Spermatozoa. Cambridge: Cambridge University Press; p. 181-194.

Jun JC, Kim BG, Cho KC (2001) Indoor induction experiment of sexual maturation of the stone flounder, Kareius bicoloratus. Tech Report West Sea Fish Res Inst Nat'l Res Dev Inst Korea. pp. 369-374.

Jun JC, Kim BG, Kim CH, Sim DS (2000) Seedling production technical development experiment of the stone flounder, Kareius bicoloratus . Tech Report West Sea Fish Res Inst Nat'l Res Dev Inst Korea. pp. 353-357.

Jun JC, Kim CH, Chung EY, Lee CH, Kim BG (2002) Influence of water temperature and salinity on early development of the stone flounder, Kareius bicoloratus from West Sea of Korea. Korean J Ichthyol 14:190-197. (in Korean)

Kim IS, Choi Y, Lee CL, Lee YJ, Kim BJ, Kim JH (2005) Illustrated Book of Korean Fishes. Seoul: Kyohak Publish Co. p. 615.

Kim IS, Kang EJ (1993) Colored Fishes of Korea. Academy Publishing Company, 477pp.

Kim YU, Kim KH (1989) Development of larvae of juveniles of the stone flounder, Kareius sbicoloratus. Korean $\mathbf{J}$ Ichthyol 1(1):98-108. (in Korean)

Lo Nostro, FL, Grier H, Meijide FJ, Guerrero GA (2003) Ultrastructure of the testis in Synbranchus marmoratus (Teleostei, Synbranchidae) the germinal compartment.
Tissue Cell 35:121-132.

Luo D, Sun JJ, Lu X, Liu LZ, Chen SJ, Li GF (2011) Comparative sperm ultrastructure of three species in Siniperca (Teleostei: Perciformes: Sinipercidae). Micron 42:884-891.

Mattei X (1988) The flagellar apparatus of spermatozoa in fish. Ultrastructure and evolution. Biol Cell 63:151-158.

Mattei X (1991) Spermatozoon ultrastructure and its systematic implications in fishes. Can J Zool 69:3038-3055.

Minami T (1984) The early life history of a stone flounder, Kareius bicoloratus. Bull Jap Soc Sci Fish 50:551-560. (in Japanese)

Moon HT (1997) Changes in species composition of surf zone fishes and early life history of, Kareius bicoloratus at Taechon Beach. Master Thesis Chungnam Nat'l Univ pp. 1-46. (in Korean)

Morales CR, Hermo L, Clermont Y (1985) Nature and functions of endocytosis in Sertoli cells of the rat. Am J Anat 173:203-217.

Mori K, Kimura S, Tojima T, Tashiro K (1986) Growth and maturity of stone flounder, Kareius bicoloratus in Ise Bay. Bull Fac Fish Mie Univ 13:151-161. (in Japanese)

Nicholls TJ, Graham GP (1972) The ultrastructure of lobule boundary cells and Leydig cell homologs in the testis of acichlid fish, Cichlasom anigrofasciatum. Gen Comp Endocrinol 19:133-146.

Poirier GR, Nicholson N (1982) Fine structure of the testicular spermatozoa from the channel catfish, Ictalurus punctatus. J Ultrastruct Res 80:104-110.

Pudney I (1993) Comparative cytology of the nonmammalian vertebrate Sertoli cell. In: Russell LD, RiswoldMD, editors. The Sertoli Cell. Saint Louis, Clearwater, FL: Cache River Press; p. 611-658.

Pudney I (1996) Comparative cytology of the Leydig cell. In: Payne AH, Hardy MP, Russell LD, editors. The Leydig Cell. Cache River Press; p. 97-142.

Romagosa E, Narahara MY, Borella MI, Parreira SF, 
H-W Kang, SH Kim, JS Chung

Fenerich-Verani N (1999) Ultrastructure of the germ cells in the testis of matrinx Brycon cephalus (Teleostei, Characidae). Tissue Cell 31:540-544.

Sylvester SR, Morales CR, Oko R, Griswold MD (1989) Sulfated glycoprotein-1 (saposin precursor) in the repro- ductive of the male rat. Biol Rerod 41:941-948.

Van Vuren JHJ, Soley JT (1990) Some ultrastructural observations of Leydig and Sertoli cells in the testis of Tilapia rendalli following induced testicular recrudescence. J Morph 206:57-63. 